\title{
Francisco Gil y Lemos, gobernador de las islas Malvinas (1774-1777)
}

\author{
Iago GIL Aguado \\ Ministerio de Asuntos Exteriores y Cooperación \\ Francisco Gil y Lemos, Governor of the Falkland Islands \\ (1774-1777)
}

\begin{abstract}
RESUMEN
La colonia de Puerto Soledad en las islas Malvinas, guarnecida de 1767 a 1811 por tropas españolas, constituía una de las posesiones más remotas y aisladas de la Monarquía Española. Aunque la existencia de la misma ha sido escasamente estudiada, era considerada en la época de gran importancia estratégica para el control de la América meridional y el paso por el Cabo de Hornos. En este artículo se reconstruye la vida y características de la colonia, estudiando el mandato del futuro virrey $y$ ministro de Marina Francisco Gil y Lemos a la cabeza de la misma. Se trata de años clave para su configuración definitiva, en los que, debido a las condiciones climatológicas extremas, se abandonó definitivamente el proyecto de establecer una colonia de población en las islas, reformándose su estructura de gobierno para convertir Puerto Soledad en un presidio destinado exclusivamente a garantizar la soberanía de España sobre el archipiélago. Son asimismo años clave para determinar la soberanía de las islas, ya que hasta 1776 existió una delicada cohabitación con la factoría británica de Port Egmont, que sería definitivamente abandonada por los ingleses durante el gobierno de Francisco Gil y Lemos.
\end{abstract}

\section{ABSTRACT}

The colony of Puerto Soledad in the Falkland Islands, garrisoned by Spain from 1767 to 1811, was one of the most remote and isolated possessions of the Spanish Empire. Despite the fact that it was considered of the utmost strategic importance at the time, it has scarcely received any serious attention. This article studies the characteristics of and daily life in the colony, analysing the governorship of the future Viceroy and First Lord of the Spanish Admiralty Francisco Gil y Lemos. During his years as Governor, plans for the establishment of a permanent civilian settlement in the Falklands were finally dropped due to the extreme climatic conditions on the islands, and Puerto Soledad assumed its definitive role as a purely military outpost intended solely to reassert Spanish sovereignty over the archipelago. Until the evacuation of Port Egmont by British forces in 1776, Francisco Gil y Lemos' governorship also coincided with a period of difficult cohabitation between Spain and Great Britain in the Falklands. 


\section{PALABRAS CLAVE}

Francisco Gil de Taboada y Lemos, Felipe

Ruiz Puente, Julián de Arriaga, Carlos III, Islas Malvinas, Puerto Soledad, Port Egmont, Francia, Inglaterra, España, Portugal, Real Armada, Cartografía.

\section{KEY WORDS}

Francisco Gil de Taboada y Lemos, Felipe Ruiz Puente, Julián de Arriaga, Charles III, Falkland Islands, Puerto Soledad, Port Egmont, France, England, Spain, Portugal, Spanish Navy, Cartography.

\section{BREVE SEMBLANZA DEL MARINO, VIRREY Y MINISTRO FRANCISCO GIL Y LEMOS (1733-1810)}

Francisco Gil y Lemos fue indudablemente una figura central, aunque hoy olvidada, de los reinados de Carlos III y, sobre todo, de Carlos IV. Confluyen en su persona dos circunstancias que convierten el estudio de la misma en cierto sentido en un viaje por terra incognita: los escasos conocimientos que se tenían hasta la fecha sobre él y esa «especie de velo» que, según uno de los máximos expertos de la época, sigue cubriendo el infravalorado reinado de Carlos IV, momento en el que ocupó sus cargos de mayor responsabilidad".

Sin embargo, el brillante cursus honorum de este bailío de la orden de San Juan lo hace acreedor de un estudio más detenido: fue un exitoso marino, virrey modélico e influyente ministro de Marina. En su carrera llegaría al grado de capitán general de la Real Armada, máximo del escalafón, del que el diplomático francés Jean-François Bourgoing diría que era equiparable a la dignidad de mariscal de Francia $^{2,}$ y al que, de acuerdo con los cálculos del historiador naval Emilio Croquer, sólo fueron ascendidos 11 oficiales a lo largo de todo el siglo XVIII ${ }^{3}$. Fue además uno de los ejemplos más destacados del «oficial científico» que intentó introducir en la Armada su maestro Jorge Juan, quien dirigía la Compañía de Guardias Marinas de Cádiz durante su paso por la misma (1752-1754). Las actividades de espionaje de Gil y Lemos en Francia e Inglaterra, así como su destacado papel en los avances científicos logrados por la Armada dieciochesca durante su mando de la

LA PARRA LÓPEZ, 2002, 23.

2 BOURGOING, 1803 2, 77: «Le grade militaire le plus éminent qu'il y ait en Espagne, est celui de capitaine général de l'armée. Il équivalait à celui de maréchal de France, avec lequel il n'était pas incompatible, puisqu'ils ont été réunis en la personne du maréchal de Berwick. Ce grade a été pendant longtemps fort peu prodigué en Espagne». ANDÚJAR CASTILLO, 1991, 182. Es fiel reflejo de ese prestigio que, según este autor, mientras que de los oficiales que llegaron a brigadieres del Ejército a lo largo del XVIII sólo el 18,3\% ostentaron títulos de nobleza, entre los capitanes generales el porcentaje era del 92,6\%. De los pocos que no tuvieron título, algunos, como Francisco Gil y Lemos y Antonio Valdés, eran religiosos, mientras que otros, como el propio Gil y Lemos o Federico Gravina, eran hermanos o hijos de títulos. Parece por ello correcta la apreciación de Andújar: «El Ejército ennoblece, y los ascensos en los más elevados empleos de la oficialidad son recompensados muchas veces con la concesión de títulos nobiliarios. Pero al mismo tiempo, estamos ante otra situación que actúa de modo paralelo. Se trata de los meteóricos ascensos que experimentarán los nobles titulados».

${ }^{3}$ Archivo de la Real Academia de la Historia (RAH), Colección Croquer, leg. 9/7431. Capitanes generales de la Armada desde el año de 1603. 
Compañía de Guardias Marinas de El Ferrol, en particular en lo relativo al establecimiento de los llamados estudios mayores o sublimes, suerte de postgrado científico para los oficiales más aventajados, son otras de sus contribuciones al progreso material de la España de la época hasta la fecha poco conocidos.

Por lo que es mejor conocido Gil y Lemos es por su labor como virrey, primero en Nueva Granada (1789) y luego en el Perú (1790-1796). Durante estos años conformaría, junto con Antonio Valdés y el conde de Revillagigedo, lo que se puede considerar un verdadero triunvirato colonial que llevó a su punto culminante el proceso de reformas que caracterizó a la América española de la segunda mitad del siglo XVIII. Son años de ambiciosas reformas administrativas y económicas, donde destaca el saneamiento de las arcas coloniales que logró nuestro personaje. Estas reformas, junto con el florecimiento cultural que caracterizó su mandato peruano y que él fomento activamente, le han valido el ser considerado por la historiografía moderna como el prototipo del virrey ilustrado. No en vano sería conocido como «el benéfico protector de las letras» por los propios peruanos 4 .

El otro momento clave de la carrera de Francisco Gil y Lemos llegaría en 1805, con su nombramiento como ministro de Marina, primero a título de interino y a partir de 1806 como propietario. Ocuparía este cargo hasta junio de 1808, siendo el único ministro del efímero primer reinado de Fernando VII que se negaría a continuar en el Gobierno bajo José Bonaparte. Durante sus tres años de ministro, le tocaría vivir el duro trance de Trafalgar así como la guerra naval de baja intensidad contra Inglaterra que seguiría a dicha batalla y duraría hasta el inicio de la Guerra de la Independencia. Se trata de un periodo de inusitada actividad, tanto naval como política, en el que Gil y Lemos acabaría jugando un papel sumamente relevante primero en la caída de Carlos IV y luego, de forma si cabe más señalada aunque esta vez infructuosa, como factótum de la resistencia al invasor francés tras la salida de Fernando VII hacia Bayona y el destierro.

\section{LA SITUACIÓN EN MALVINAS Y EL NOMBRAMIENTO DE GIL Y LEMOS COMO SU GOBERNADOR}

En este artículo nos vamos a concentrar en otro episodio escasamente conocido de la vida de Francisco Gil y Lemos, su gobierno de las islas Malvinas entre 1774 y 1777 . Se trataba de una de las posesiones más remotas y aisladas de la Monarquía española, pero considerada en la época de gran importancia estratégica. Hasta tal punto era así que en 1766 el conde de Aranda escribiría que la soberanía sobre las Malvinas, disputada por el Reino Unido, era «el [asunto] más crítico que se haya ofrecido a la Corona; pues a mi dictamen no igualaría la pérdida de una isla entera como Cuba, o Puerto Rico; porque aunque grande no estaría

4 Archivo General de Indias (AGI), MP, Perú-Chile, n 123. Plano de la Pampa de Sacramento elaborado por Manuel Sobreviela y dedicado a Francisco Gil y Lemos, benéfico protector de las letras. 
tan en riesgo la Tierra Firme, como lo quedará la parte meridional para su más difícil socorro» 5 .

Curiosamente, la colonización de las islas Malvinas no había sido iniciada ni por España ni por Inglaterra, sino por Francia. El 5 de abril de 1764 el ilustre matemático y militar francés Louis-Antoine de Bougainville había bautizado con el nombre de Port Louis, en honor de su monarca, una pequeña colonia que acababa de establecer en la isla de la Soledad, una de las dos principales del archipiélago ${ }^{6}$. Tras enérgicas protestas de la Corte de Madrid, ésta logró finalmente la evacuación de la colonia francesa, no sin antes pagar una cuantiosa indemnización a los «inversores» franceses que habían financiado la expedición de Bougainville ${ }^{7}$. Port Louis, rebautizado atinadamente Puerto Soledad, pasó a ser ocupado por España el 2 de abril de 1767, asumiendo el mando de la colonia el capitán de navío Felipe Ruiz Puente, primer gobernador español de las islas Malvinas e inmediato antecesor de Gil y Lemos en el cargo ${ }^{8}$.

Paralelamente a las negociaciones entre Madrid y París sobre el futuro de Port Louis, y hecho ignorado por ambas capitales, Inglaterra había decidido mandar una expedición a las «Falkland», bajo las órdenes del capitán John Byron, abuelo del ilustre poeta ${ }^{9}$. Así fue como a principios de 1765 , y despreciando los títulos de soberanía de España, se fundaba la colonia de Port Egmont, bautizada así en honor del a la sazón primer lord del Almirantazgo, el conde de Egmont. Diversos encuentros entre barcos franceses e ingleses en las islas, así como rumores persistentes en Londres sobre expediciones secretas al Mar del Sur, pronto hicieron saltar las alarmas en Madrid, donde se empezó a temer la existencia de un establecimiento británico en la zona del Estrecho de Magallanes. Como resultado de los citados rumores, se despacharon diversas expediciones en búsqueda de la supuesta factoría británica, dos de ellas lideradas por el entonces teniente de navío Gil y Lemos a bordo de la fragata Santa Rosa ${ }^{10}$. Dados los escasos conocimientos geográficos de la época y lo imprecisa que era la información facilitada por el príncipe de Masserano, embajador de Carlos III en Londres, en un principio no se sabía si el establecimiento inglés estaba situado en la costa de la Patagonia, en las islas Malvinas o en unas misteriosas islas llamadas «FaIkland», que se pensaba eran un archipiélago distinto al de las Malvinas.

5 GIL MUNILLA, 1948, 35-37. Citando el dictamen sobre las Malvinas del conde de Aranda, a la sazón presidente del Consejo de Castilla, de 15 de septiembre de 1766 [AHN, Estado, legajo 2858].

6 CERVERA PERY, $1986,97$.

7 URTASUN, 1920, 24. FERRER DEL RíO, 1856, 63. La compensación ascendió a las 603.000 libras tornesas en las que se calcularon las pérdidas ocasionadas, más un interés del cinco por ciento que se pagó sobre dicha suma.

8 AGI, Indiferente, 412, doc. 75. Minuta de la Secretaría del Despacho.

9 MAESO BUENASMAÑANAS (Madrid, 2004): 110.

10 Sobre la primera expedición de Gil y Lemos a las Malvinas ver ibíd.. 192/194 y 664. RATTO, 1930, 85/88. La segunda expedición de Gil y Lemos a las Malvinas, que inició a finales de 1769, no se ha sido reflejada en la literatura sobre las expediciones españolas en la región. 
Finalmente, una vez localizado Port Egmont por los españoles, el gobernador de Buenos Aires, Francisco Bucareli, mandaría una expedición, a las órdenes del comandante del apostadero de Montevideo, Juan Ignacio de Madariaga, y compuesta de cuatro fragatas (entre ellas la Santa Rosa al mando de Gil y Lemos), un chambequín y un bergantín, a desalojar a los británicos, operación que efectivamente se llevó a cabo con éxito en el invierno austral de 1770.

Pese a la feliz conclusión de la expedición Madariaga, la Corte de Madrid, que en su día había ordenado a Bucareli que procediera a desalojar, si fuera menester por la fuerza, Port Egmont ${ }^{11}$, ahora dio marcha atrás. Carlos III, movido por serias y fundadas dudas sobre la fiabilidad de la alianza francesa, el 17 de septiembre de 1770 decidió la evacuación de Port Egmont, para así evitar el rompimiento con Inglaterra ${ }^{12}$. Dos días más tarde se cursaban órdenes a ese efecto a Felipe Ruiz Puente, mandándole desalojar el antiguo establecimiento británico, previa eliminación de todo rastro de su ocupación por Inglaterra. No debería éste ofrecer resistencia alguna a un intento de restablecimiento británico en Port Egmont, si bien se le ordenaba defender Puerto Soledad en caso de una represalia inglesa ${ }^{13}$.

Según ha descrito detalladamente Octavio Gil Munilla en su estudio del conflicto de 1770 con Inglaterra, a raíz del incidente se entablaron largas negociaciones diplomáticas entre las tres cortes, que resultarían en lo que él ha descrito como la "defección francesa", que sería seguida por la "claudicación española» ${ }^{14}$. Fue ésta una decisión lógica, ya que España no estaba en condiciones de enfrentarse sola a la Gran Bretaña, y trascendental en la medida en que Carlos III y sus consejeros se vieron obligados a reconsiderar el valor de la alianza francesa ${ }^{15}$. El resultado inme-

11 AGI, Indiferente, 412. Real Orden de 25 de febrero de 1768 de Julián de Arriaga a Francisco Bucareli: «Me manda S.M. encargar eficazmente a V.E. esté muy a la mira, para no permitir establecimiento alguno de los ingleses; y que de los que tengan hechos, los expela por la fuerza, si no sirven las amonestaciones, arreglado a las leyes, y sin necesitar más orden, ni instrucción, ni observar en esto más medida que la precisa de sus propias fuerzas con las que ellos tengan, por no exponerse con inferioridad a no lograr el fin; para en cuyo caso, y el de la premeditación de otras peores consecuencias que V.E. pueda deducir en el estado de esas provincias, usará del medio de protestas y reconvenciones de su intentada usurpación, manifestándoles se abstiene de hechos por dar parte a S.M. y esperar sus Reales ordenes». Existe otra versión en AGI, Buenos Aires, 552, aneja a las instrucciones de Juan Ignacio de Madariaga a Francisco Gil y Lemos, Buenos Aires, 9 de noviembre de 1769.

12 FERRER DEL RíO, 1856, 86. Este autor nos indica que Luis XV, decidido a evitar un enfrentamiento con Inglaterra e influido por su amante, la Du Barry, optó por la caída del duque de Choiseul, dispuesto a respetar la alianza. Al parecer lo explicaría a su primo Carlos III con las palabras: «Mi ministro quería la guerra; yo no la quiero».

13 AGI, Indiferente, 412. Reales Órdenes remitidas por Julián de Arriaga a Felipe Ruiz Puente, San Ildefonso, 19 y 22 de septiembre de 1770.

14 GIL MUNILLA, 1948, 124/125.

15 PALACIO ATARD, 1945, 290/291. «En realidad, el Tratado de 1761 tiene una vida eficaz más corta. La alianza francesa no dio los resultados que se imaginaron. Precisamente en el asunto de las Malvinas se puso en evidencia hasta dónde podía servir la amistad con nuestros vecinos. Y desde entonces se inicia un apartamiento de este sistema político por parte del Gobierno español, que se fue agudizando al caer Choiseul del Ministerio francés. Luego, con la salida de Grimaldi y el Gobierno de Floridablanca, se iniciará otra etapa, con nuevas orientaciones para la política exterior. Después de 1770 el Pacto de Familia era como una vieja escopeta colgada en la habitación de un cazador anciano, que sirve de adorno y evoca recuerdos de otros tiempos". 
diato fue la restitución pública a los británicos de Port Egmont —aunque sin reconocimiento de una eventual soberanía-, a cambio de lo cual los ingleses empeñaron su palabra, «de carácter privado, no ministerial», comprometiéndose con nuestro embajador en Londres a proceder en un futuro próximo, una vez calmada su opinión pública, a abandonar las Malvinas ${ }^{16}$. Con esta promesa en mano, un año más tarde, el 11 de septiembre de 1771, se procedió a entregar Port Egmont a los británicos ${ }^{17}$.

Aunque se ignorase la promesa secreta dada por su gobierno de abandonar en breve Port Egmont, la actuación británica no había estado exenta de críticas en su propio país. Entre las voces críticas se encontraba una de las mentes más preclaras y de las plumas más incisivas del siglo, Samuel Johnson, quien en 1771 recordaría a sus compatriotas lo siguiente:

«The value of the thing disputed may be very different to him that gains and him that loses it. The Spaniards, by yielding Falkland's island, have admitted a precedent of what they think encroachment; have suffered a breach to be made in the outworks of their Empire [...] We have, by obtaining a disavowal of Bucareli's expedition, and a restitution of our settlement, maintained the honour of the crown, and the superiority of our influence. Beyond this, what have we acquired? What, but a bleak and gloomy solitude, an island, which not the southern savages have dignified with habitation; where a garrison must be kept in a state that contemplates with envy the exiles of Siberia; of which the expense will be perpetual, and the use only occasional; and which, if fortune smile upon our labours, may become a nest of smugglers in peace, and in war the refuge of future buccaneers ${ }^{18}$.

Sea de ello lo que fuere, ésta era la situación —con España ocupando Puerto Soledad e Inglaterra Port Egmont-cuando, el 2 de diciembre de 1772, tras disfrutar de un breve permiso en la Corte ${ }^{19}$, se le comunicó a Gil y Lemos su nombramiento como gobernador de las islas Malvinas, con sueldo de 4.000 pesos fuertes anuales (80.000 reales de vellón) ${ }^{20}$. Todo parece indicar que fue gracias al ministro

16 GIL MUNILLA, 1948, 143.

17 BLANCO NÚÑ̃EZ, 2004, 98.

18 JOHNSON, 1771, 39/41.

19 Archivo General de Marina (AGM), legajos 2853 y 2854.

20 Archivo Condal de Taboada (ACT), Casa de Des, caja 5, legajo 2. Cédula de nombramiento de Gil y Lemos como gobernador de las islas Malvinas: «Don Carlos, por la Gracia de Dios, rey de Castilla, de León, de Aragón, de las Dos Sicilias, de Jerusalén, de Navarra, de Granada, de Toledo, de Valencia, de Galicia, de Mallorca, de Sevilla, de Cerdeña, de Córdoba, de Córcega, de Murcia, de Jaén, de los Algarbes, de Algeciras, de Gibraltar, de las Islas de Canaria, de las Indias Orientales, y Occidentales, Islas, y Tierra Firme del Mar Océano, archiduque de Austria, duque de Borgoña, de Brabante, y Milán, conde de Abspurg, Flandes, Tirol, y Barcelona, señor de Vizcaya y de Molina, etc.. Por cuanto atendiendo al mérito y buenos servicios de vos, don Francisco Gil, y Lemos, capitán de fragata de mi Real Armada, he venido en elegiros, y nombraros, como por el presente os elijo, y nombro, para que relevéis al capitán de navío don Felipe Ruiz Puente, de su destino de gobernador de las islas Malvinas, pertenecientes a mi Corona, y sirváis este empleo, con las mismas preeminencias, facultades, y sueldo de cuatro mil pesos anuales, que le ha obtenido el expresado don Felipe Ruiz Puente. Por tanto mando al gobernador, y capitán general de las provincias del Río de la Plata, y ciudad de Buenos Aires, bajo cuyas órdenes debéis ejercer el referido cargo, que verificada que sea vuestra presentación en el citado destino, haga que os reconozcan por tal gobernador de las islas Malvinas, los oficiales, ministros, sargentos, cabos, y soldados, y demás dependientes existentes en ellas, obedeciendo las órdenes que les diereis de mi servicio por escrito, u 
de Marina, Julían de Arriaga, como él sanjuanista, que Gil y Lemos obtuvo este nuevo cargo ${ }^{21}$. No era una bicoca, pero indudablemente era un puesto que, en aquellas circunstancias, le ofrecía una oportunidad de perfilarse.

El nuevo mando, aunque modesto, situaba a Gil y Lemos en primera línea de la defensa imperial. Como vimos, Port Egmont se encontraba de nuevo ocupado por los ingleses, si bien con la promesa de proceder a su evacuación una vez tranquilizada la opinión pública londinense. Era un puesto duro en extremo - detalle que evidentemente no ignoraba Gil y Lemos-, lo que reflejaba en su desesperación Ruiz Puente en su correspondencia con Buenos Aires y Madrid. Éste había escrito ya en 1769 a Arriaga: «Baste de Malvinas, porque son tales, que puedo asegurar a V.E. con toda verdad, que no hay en el universo habitado presidio semejante: es la casa más ruin, y estéril que se puede imaginar ${ }^{22}$. Dos años más tarde seguía lamentándose de su triste destino: «Hallándome en este gobierno va para cinco años, que se cumplirán a las resultas de este recurso, sufriendo, con detrimento total de mi salud y espíritu, las precisas y continuas penalidades de un temperamento sin estación, en un país estéril, desabrido y triste; me considero en el justo y bien visto caso de acudir a la real clemencia de S.M. por mi relevo» ${ }^{23}$.

Las condiciones en el presidio eran francamente duras. Como señalaba el contador de la colonia, habían fracasado todos los esfuerzos por cultivar sus tierras:

«Yo traje de Montevideo una porción de tierra para hacer experimentos deseoso de lograr alguna cosecha, pero nada he adelantado porque aunque todo nace, tanto en aquella tierra como en ésta, la falta de calor y de estaciones impide el progreso favorable de la planta, y los fríos, granizo, hielos, y fuertes vientos que desordenadamente las mortifican, hacen que se sequen apenas nacen [...] sólo la col he visto hasta ahora que prevalezca y muy tierna, pero se hace forzoso traer semilla de otra parte para la sucesión» ${ }^{24}$.

de palabra, sin réplica, ni dilación alguna, y que os guarden, y hagan guardar todas las prerrogativas, y gracias que os tocan [...] Dado en Madrid a 2 de diciembre de 1772. Yo El Rey". En lo referente a la conversión de pesos fuertes a reales de vellón, cabe señalar que por una Real Pragmática dada en Aranjuez el 11 de mayo de 1737 por Felipe V, y publicada en Madrid el día 17, se estableció que «el peso de plata valga 20 reales de vellón, el medio peso 10 y a este respecto las demás monedas menores con el cuño de Columnas y Mundos... ». [Autos Acordados, libro V, título XXI, auto LXXII]

21 Sobre la relación entre Julián de Arriaga y Francisco Gil y Lemos, véase la correspondencia de ambos que se conserva: Archivo General de Simancas (AGS), Marina, 412-2. Carta de Francisco Gil y Lemos a Julián de Arriaga, Cádiz, 20 de noviembre de 1770. AGI, Buenos Aires, 552. Carta Francisco Gil y Lemos a Julián de Arriaga, Montevideo, 18 de julio de 1770. AGI, Buenos Aires, 553. Carta de Francisco Gil y Lemos a Julián de Arriaga, Madrid, 9 de diciembre de 1772. En esta última, en la que agradece a Arriaga su nombramiento como gobernador de las Malvinas, Gil y Lemos escribe al ministro: «Persuadido, que esta nueva gracia con que la piedad del rey honra la cortedad de mi mérito, es puro efecto del favorable influjo de V.E., le suplico viva cierto de mi eterno reconocimiento y de que para el puntual y exacto desempeño de mi nuevo empleo, nada me quedará que practicar».

22 AGI, Buenos Aires, legajo 552. Carta de Felipe Ruiz Puente a Julián de Arriaga, Malvinas, 10 de febrero de 1769.

23 AGI, Buenos Aires, legajo 553. Carta de Felipe Ruiz Puente a Julián de Arriaga, Malvinas, 27 de marzo de 1771.

24 AGI, Buenos Aires, 553. Resumen del costo anual que a lo menos tienen al rey la isla y Puerto de la Soledad de Malvinas. Juan de la Piedra, Puerto Soledad, 16 de marzo de 1773. 
El resultado de una dieta harto monótona y de las largas estancias en la isla era que «toda la gente de tierra, y mar vive repugnante por la continuada enfermedad del escorbuto que proviene de la continuación de carne salada, falta de verduras y rigor del clima» ${ }^{25}$. La situación era tal que se produjeron diversos intentos de deserción - sorprendentes teniendo en cuenta que la única forma de escapar de aquel infierno era pasarse a los ingleses en Port Egmont-, y en 1771 los presidiarios y parte de la guarnición estuvieron a punto de amotinarse, tentativa que Ruiz Puente pudo sofocar a duras penas y en el último momento. Resultó necesario, en esa ocasión, relevar a la totalidad de la guarnición ${ }^{26}$. Aunque estratégicamente importantes, las islas estaban resultando menos útiles de lo que en un principio se había pensado y su relevancia distaba mucho de la que inicialmente les había atribuido el conde de Aranda. La gran distancia que las separaba de cualquier lugar habitado, lo extremado de su clima, la escasa feracidad de sus tierras y lo inclemente de los mares del sur hacían dudar sobre su viabilidad, lo que se vería confirmado en 1776 cuando los ingleses abandonaron Port Egmont definitivamente.

La travesía del Atlántico la realizó Gil y Lemos a principios de 1773 y a bordo de la fragata de su mando, llamada la Asunción. Fue un viaje accidentado en el que no faltó algún episodio de impericia marinera protagonizado por el propio don Francisco ${ }^{27}$. Apenas cruzado el Río de la Plata e instalado en la relativa comodidad de Buenos Aires, Gil y Lemos se reunió con el gobernador cesante Ruiz Puente, quien había abandonado apresuradamente la colonia en cuanto le llegó noticia de que se había nombrado un sucesor. Conscientes de la escasa viabilidad de una colonia de población, ambos se mostraron ansiosos de elaborar un nuevo proyecto de gobierno para las islas con objeto de reducir los gastos que éstas suponían para el Real Erario. Consta claramente que Ruiz Puente era escéptico en cuanto a la utilidad de las islas, puesto que ya en 1769 había escrito a Arriaga que:

«Esta posesión cada vez me parece más y más inútil y sin duda alguna muy costoso su establecimiento. Contemple V.E. lo que es, que no obstante lo gastado

25 AGI, Buenos Aires, 553. Informe de Felipe Ruiz Puente y Francisco Gil y Lemos anejo al despacho n 305 de Juan José de Vértiz a Julián de Arriaga, Buenos Aires, 29 de abril de 1773.

26 AGI, Buenos Aires, 53. Despacho n 193 de Juan José de Vértiz a Julián de Arriaga, Buenos Aires, 15 de marzo de 1772. Vértiz informaba del «enorme atentado de levantamiento que la mayor parte de los presidiarios de aquella colonia, y algunos soldados de su guarnición con el teniente del Regimiento de Infantería de Mallorca don Nicolás de Arteta a la testa, parece tenían concertado emprender la noche del 20 al 21 del último octubre; en la cual noticioso de aquella determinación, pudo asegurar la cabeza, y secuaces de dicho crimen, y que se procediese a la sumaria averiguación de este suceso».

27 AGM, legajo 2888. El 16 de noviembre de 1772 se le había concedido el mando de la fragata Nuestra Señora de la Asunción. AGI, Buenos Aires, 53. Carta de Francisco Gil y Lemos a Julián de Arriaga, Montevideo, 20 de abril de 1773: «En el canal del Río se hallaban fondeadas, y prontas para regresar a España, la Santa Bárbara y Nuestra Señora del Carmen, y queriendo pasar por entre sus proas y la tierra a fin de asegurar esta fragata de los vientos sudoestes que son aquí tan fuertes como improvistos, ha tocado por haber varado el Río más de lo regular; pero salió con el beneficio de algún alijo. Para reconocer el daño se le desabrió la quilla, y verificó que sólo en parte de ella había padecido, y actualmente se está habilitando de ella, y otras obras indispensables para su permanencia, y campañas de Malvinas». 
se puede decir, que nada hay hecho en ella a la hora de ésta ni es fácil como quiera el conseguirlo; porque aquí nada en suma se produce ni logra, en una palabra señor, a excepción del puerto y el pasto, nada, nada vale esta isla; pues ni aun terreno firme, ni piedra apropósito tiene para fabricar, y todo lo que está en ser se halla al caer» 28 .

A la convicción de la escasa utilidad de las islas manifestada por el gobernador saliente se sumaba ahora el afán economizador de su sucesor, quien a lo largo de su carrera siempre se afanó por reducir los dispendios de la Real Hacienda. Por ello, poco nos debe sorprender que ambos convinieran en la necesidad de reducir el establecimiento y decidieran elaborar un proyecto de reforma del mismo. En palabras de Gil y Lemos dirigidas a Arriaga, «como los medios propuestos conspiran al menor dispendio del Real Erario, sin ceder en perjuicio de la defensa, no he tenido embarazo en condescender en que por la vía de V.E. los hiciere presentes a S.M. como lo ejecuta, sirviéndome de inductivo para asentir la ventaja que considero al real servicio, que es mi único objeto indistintamente en todas partes y en cualquiera parte en todos términos» 29 .

El proyecto que remitieron ambos a Madrid reproducía, a grandes trazos, el modelo que los británicos habían establecido para Port Egmont y que se limitaba a guarnecer el presidio con las tripulaciones de los buques allí destinados ${ }^{30}$. Ello permitiría ahorrarse la presencia de un destacamento fijo y de una administración propia, estructura que carecía de razón de ser desde el momento en que se había decidido renunciar a mandar colonos a las islas. La propuesta elevada por Ruiz Puente y Gil y Lemos se puede resumir de la forma siguiente:

1) Estacionamiento continuo en Puerto Soledad de una fragata de guerra con una tripulación de 180 hombres. A ésta se sumarían dos embarcaciones menores, sin tripulaciones propias, que permitirían garantizar la comunicación con el Río de la Plata en caso de necesidad y facilitarían la exploración de la costa. Los tripulantes de la fragata constituirían la dotación de las islas y su capitán actuaría de facto de gobernador de las islas, lo que permitiría a la Real Hacienda ahorrarse los sueldos de la guarnición fija y del gobernador.

2) Dicha fragata y su tripulación deberían ser relevadas anualmente, evitando así el hastío de la tripulación y permitiendo el correcto mantenimiento del buque. En total serían necesarias dos fragatas, una estacionada en Puerto Soledad y la otra, que aseguraría el relevo, con base en el Río de la Plata. Al cabo de dos años, las dos fragatas y sus tripulaciones serían relevadas y volverían a la Península, donde los buques podrían ser carenados más económicamente.

28 AGI, Buenos Aires, 552. Carta de Felipe Ruiz Puente a Julián de Arriaga, Malvinas, 10 de febrero de 1769 .

29 AGI, Buenos Aires, 553. Carta de Francisco Gil y Lemos a Julián de Arriaga, Buenos Aires, 4 de mayo de 1773.

30 En un principio los ingleses habían destinado cuatro fragatas a la colonia. Éstas se turnaban, permaneciendo dos en Port Egmont mientras las otras realizaba el viaje de ida y vuelta al Reino Unido. Luego parece que se redujo su número a dos fragatas, una constantemente presente en el establecimiento. 
Esta propuesta, al margen de reducir gastos, debía mejorar la defensa de la colonia, al establecerse la presencia continua de una de las fragatas en el puerto, con lo que «abrigada la fragata de las baterías de tierra podrán ambas fuerzas unidas sostenerse, y rechazar mejor un ataque». Por añadidura, se preveía que, «respecto no debe hacer fuego la fragata más que de un costado, puede la tripulación que debe ejercitarse en la maniobra, ejecutarlo en las baterías, evitando así los sueldos que disfrutan los que hoy son precisos para el fin». Todo ello se lograría mejorando asimismo la moral de la guarnición, ya que «a todos se les desvanecerá el terror de aquella navegación, y destino, con el consuelo del determinado tiempo " ${ }^{31}$. Aunque el informe no incluía una memoria económica, sabemos que el contador de la colonia de Puerto Soledad, Juan de la Piedra, calculaba por esas fechas que el coste del establecimiento ascendía a 149.932 pesos anuales (casi 3.000.000 reales de vellón). Era una cifra sustancial, si bien hay que tener en cuenta que de ella sólo 38.060 pesos correspondían a los sueldos de los empleados de la colonia propiamente dicha, cuyos cargos se amortizaban gracias a la nueva planta. Los 111.172 pesos restantes correspondían al «costo de dos fragatas [...] que no se les considera otro motivo para andar en estos mares que las atenciones de esta [colonia]» ${ }^{32}$, gasto que se mantendría de aprobarse el nuevo plan.

En Madrid hubo quien criticó el plan, porque «no se expresa a cuánto llegará el ahorro que se supone, ni tampoco se señalan cuáles son los empleados que deberían separarse ${ }^{33}$. Por orden de Arriaga se formaría una comisión para estudiar el plan y concretar su contenido, integrada por el entonces director general de la Real Armada, Andrés Reggio, por el jefe de escuadra y futuro ministro del ramo Pedro González de Castejón y por Felipe Ruiz Puente, restituido a España. Éstos acabarían endosando la mayoría de las propuestas hechas, concretando algunos detalles de la misma, y concluirían que, «no es dudable el menor gasto, que ocasionará a la Real Hacienda el método propuesto por los empleos de tierra, que se suprimen, quedando con la misma defensa, que en aquel caso tendrían, mayor que la que hoy tienen, por la falta de existencia fija de la fragata, y con superiores fuerzas, a las con que se halla el establecimiento que en aquel paraje tienen los ingleses, pues sólo consisten en una fragata de veinte cañones, para el servicio de mar, y tierra» ${ }^{34}$. Pese a las críticas mencionadas, el plan remitido formaría el núcleo de la reforma de la colonia implementada cuando Gil y Lemos cesó en el cargo tres años más tarde, y Arriaga tuvo a bien informar a

31 AGI, Buenos Aires, 553. Informe de Felipe Ruiz Puente y Francisco Gil y Lemos anejo al despacho n 305 de Juan José de Vértiz a Julián de Arriaga, Buenos Aires, 29 de abril de 1773.

32 AGI, Buenos Aires, 553. Resumen del costo anual que a lo menos tienen al rey la isla y Puerto de la Soledad de Malvinas. Juan de la Piedra, Puerto de la Soledad, 16 de marzo de 1773.

33 AGI, Buenos Aires, 553. Minuta de la Secretaría de Estado de Marina sobre el plan de Felipe Ruiz Puente y Francisco Gil y Lemos, 30 de agosto de 1773.

34 AGI, Buenos Aires, 553. Informe de Andrés Reggio, Pedro González de Castejón y Felipe Ruiz Puente, Isla de León, 10 de septiembre de 1773. 
nuestro protagonista que «se ha dignado el rey de aprobar el dictamen que Vuestra merced produjo en ella» 35 .

Puede parecer paradójico que Gil y Lemos, tras haber obtenido el nombramiento como gobernador de las islas, se estrenara en su nuevo cargo proponiendo una reforma que, efectivamente, suponía la supresión del cargo de gobernador que tan efusivamente había agradecido a su correligionario Arriaga unos meses antes. No sería descabellado pensar que su objetivo era evitar su perpetuación en el cargo, riesgo muy real vista la experiencia de Ruiz Puente, quien pasó más de cinco años a la cabeza de la colonia. El hecho de que no tomara posesión del mando hasta principios de 1774, alegando en mayo de 1773 que «considerando este gobernador [de Buenos Aires] que la presente estación es la más rigurosa, ha determinado suspender la salida de la fragata que debe conducirme y conducir víveres, y otros géneros a Malvinas, hasta que empiece a ceder ${ }^{36}$, refuerza la impresión de que tampoco tenía excesiva prisa por pasar a Puerto Soledad.

No obstante, sería un error considerar la propuesta de reforma redactada por Ruiz Puente y Gil y Lemos como una mera estratagema para reducir al mínimo el paso de este último por las islas. El informe contenía elementos característicos de lo que sería la visión política de don Francisco cuando llegara a ocupar las más altas magistraturas: en lo civil, reducción al máximo de gastos innecesarios, incluso si suponía actuar en detrimento de su propio mando; en lo militar, supresión de unidades que no fueran estrictamente indispensables para la defensa colonial, desconfianza en los gastos en fortificaciones terrestres y en una defensa estática, y convicción de que España sólo podría mantener su imperio colonial con una Armada potente que le asegurara su condición de gran potencia naval en Europa ${ }^{37}$. Dicha propuesta, tendente a concentrar la defensa

35 AGI, Buenos Aires, 553. Borrador de carta de Julián de Arriaga a Francisco Gil y Lemos, San Ildefonso, 30 de agosto de 1773. MARTíNEZ MONTERO, 1968, 4/5. Según este autor, sería este proyecto el que consolidaría definitivamente a Montevideo como principal base naval del Atlántico sur: «Además de las funciones generales y comunes de defensa militar de los dominios del rey y de la policía fiscal del mar, cada apostadero tuvo una misión particular que cumplir y en la cual debe buscarse la causa de su institución. Para el de Montevideo, ella radica en la necesidad de mantener la posesión de las islas Malvinas dentro de las posesiones españolas [...] Logrado el propósito de la evacuación de las islas en las circunstancias que más adelante indicaremos, una Real Orden firmada en San Ildefonso el 9 de agosto de 1776, dispuso las medidas que representarían el principio del establecimiento del apostadero de Montevideo, mandando que en adelante dos fragatas de guerra con base en tal punto se turnarían en la vigilancia permanente de las islas y en el resguardo del Plata».

36 AGI, Buenos Aires, 553. Carta de Francisco Gil y Lemos a Julián de Arriaga, Buenos Aires, 4 de mayo de 1773 .

37 AGI, Lima, 691. Carta de Francisco Gil y Lemos a Ambrosio O’Higgins, Lima, 28 de agosto de 1790. Indudablemente recordando sus experiencias en las Malvinas, Gil y Lemos escribiría al capitán general de Chile las siguientes palabras: «V.S. se queja justamente [...] del abandono de Valdivia, en donde se hallan las cureñas inutilizadas, las esplanadas destruidas, los cañones por tierra, sin haber uno habilitado para hacer fuego; la brigada sin instrucción, ni conocimiento alguno para su manejo, etc. [...], y éste es el destino de la mayor parte de las fuerzas en semejantes parajes, cualesquiera que sean las providencias que se den, y las sumas que se gasten. Lo que no se pierde por desidia, lo arruina la 
de las islas en una pequeña fuerza naval, que podría desplazarse en cualquier momento para servir en otros escenarios bélicos menos distantes y adversos, era plenamente coherente con lo que sería su posterior labor de gobierno.

\section{SANGRE, SUDOR Y LÁGRIMAS}

«Este miserabilísimo destino, a donde por reemplazo de un enfermo me trajo mi desgracia» 38 .

Felipe Ruiz Puente.

No es difícil imaginarse el estado de ánimo de Gil y Lemos cuando, el 1 de enero de 1774, desembarcaba de la fragata de su mando la Asunción para asumir el gobierno de la colonia de Puerto Soledad. Como había indicado unos meses antes en su informe conjunto con Ruiz Puente: «Lo estéril de aquellas islas cerró la puerta a la esperanza de que pueda fructificar por más cuidadosamente que se cultive; y esto lo han confirmado varios experimentos hechos en todos los años, y cada año en todas las estaciones» ${ }^{39}$. A estas alturas ya se había abandonado cualquier esperanza de crear una colonia capaz de prosperar y un día autoabastecerse. El propio Gil había asumido que carecía de sentido desarrollar la colonia más allá de lo que fuera indispensable para asegurar la soberanía española (cuyo futuro, de verse de nuevo cuestionada por los ingleses, indudablemente se resolvería en otros escenarios, fueran éstos bélicos o diplomáticos). Con tan pocas perspectivas de futuro para el establecimiento, los objetivos de Gil y Lemos eran claros y concisos: el principal, sostener la soberanía de iure de España con una presencia de facto sobre el terreno; pero también el vigilar Port Egmont, verificando que los ingleses procedían a su evacuación pasado un tiempo prudencial; y, finalmente, seguir explorando las islas, entre otras razones porque el conocimiento cartográfico era considerado en aquellos tiempos un título adicional de soberanía ${ }^{40}$. Sin embargo, es indudable que la mayor parte de su energía la dedicaría durante los tres próximos años a asegurar la supervivencia de los hombres a sus órdenes en un paraje tan hostil, velando por el mantenimiento de la precaria disciplina de la colonia.

\footnotetext{
intemperie, y cuando llega el caso no se halla nada con que hacer frente al enemigo, con la diferencia que él empieza a gastar cuando nos ataca, y nosotros nos hemos arruinado antes de empezar a resistirlo [...] Gastar cuanto produce, y puedan producir en muchos años estos dominios de S.M. en fuerzas inmóviles para defendernos de fuerzas ambulantes, es someternos a la dura necesidad de resistir al enemigo dónde y cuándo le acomode atacarnos, es dejarle la elección, y con ella la seguridad del suceso. Es ponernos en la precisión de temerlo siempre, sin hacernos de él jamás temidos».

38 AGI, Buenos Aires, 552. Carta de Felipe Ruiz Puente a Juan Ignacio de Madariaga, Malvinas, 18 de febrero de 1770 .

39 AGI, Buenos Aires, legajo 553. Informe de Felipe Ruiz Puente y Francisco Gil y Lemos anejo al despacho n 305 de Juan José de Vértiz a Julián de Arriaga, Buenos Aires, 29 de abril de 1773.

40 CAPEL (Madrid, 1988): 109.
} 
Como haría en el futuro cuando fue llamado a asumir responsabilidades mucho más importantes, su primera preocupación fue la de conocer las circunstancias exactas de la colonia: «Luego que me posesioné en el gobierno de esta isla hice un exacto reconocimiento del estado de defensa en que se hallaba el puerto, y de las municiones, repuesto en almacenes, y víveres existentes» ${ }^{41}$. Estaba siguiendo su propia máxima, expresada cuando ya era virrey del Perú, de que, «para que las providencias políticas, económicas y de buen gobierno produzcan el efecto conveniente, y no se empeoren tal vez los mismos males que desean corregirse, es indispensable conocer la situación y extensión del país, la población que contiene $[\mathrm{y}]$ el estado de civilización en que se halla» ${ }^{42}$. De ahí que sepamos el estado exacto de la colonia, que contaba en esos momentos con 115 habitantes, de los cuales 44 eran soldados y 22 presidiarios, además de 3 mujeres y 11 niños, resultado de la colonización francesa que había intentado establecer familias en dicho paraje. La pequeña administración civil la componía el propio gobernador, el ministro de la Real Hacienda y dos guardalmacenes, mientras que la oficialidad la componían el capitán del puerto, un pilotín de la Real Armada, un capitán y un teniente de infantería y un alférez de artillería, que haría las veces de edecán de Gil y Lemos ${ }^{43}$. Puerto Soledad contaba en esos momentos con 23 edificaciones, incluyendo la casa del gobernador, un hospital y una capilla "de tepes con 2 pequeñas habitaciones para los capellanes todo arruinado y incapaz de componerse». De toda la descripción se desprende un aire de dejadez y abandono. Las tres baterías de Santiago, San Carlos y San Felipe que defendían la colonia no tenían «más que una arruinada muralla de tepes a barbeta extremamente baja y que carecen de depósitos seguros para la pólvora y pertrechos de artillería, y así mismo de casas matas para resguardo de la gente que no se halle de acción en tiempo de combate, por cuyas circunstancias están actualmente indefensas a cualquier acometimiento que se intente por mar o tierra». Los almacenes generales «necesitan casi reedificarse», el de pólvora «todo deteriorado», los cuarteles «reducidos y arruinados», las barricas o chozas de tepes que servían para alojamiento del resto de la población «todas deterioradas» ${ }^{44}$. Durante su gobierno encomendaría a los pilotos de la Real Armada Juan Calleja y Narciso Sánchez la elaboración de un plano de Puerto Soledad que nos da una idea de lo que suponía aquel exiguo presidio, incluyendo la propia residencia del gobernador, situada en un pequeño promontorio que dominaba el centro de la bahía ${ }^{45}$.

\footnotetext{
41 AGI, Buenos Aires, 553. Francisco Gil y Lemos a Julián de Arriaga, Malvinas, 4 de abril de 1774.

42 AGI, Lima, 703. Despacho no 139 de Francisco Gil y Lemos al marqués de Bajamar, Lima, 5 de noviembre de 1792 .

43 AGI, Buenos Aires, 553. Carta de Francisco Gil y Lemos a Julián de Arriaga, Malvinas, 4 de abril de 1774 .

44 lbíd.

45 Archivo del Museo Naval de Madrid (AMN), 49-A-14.
} 


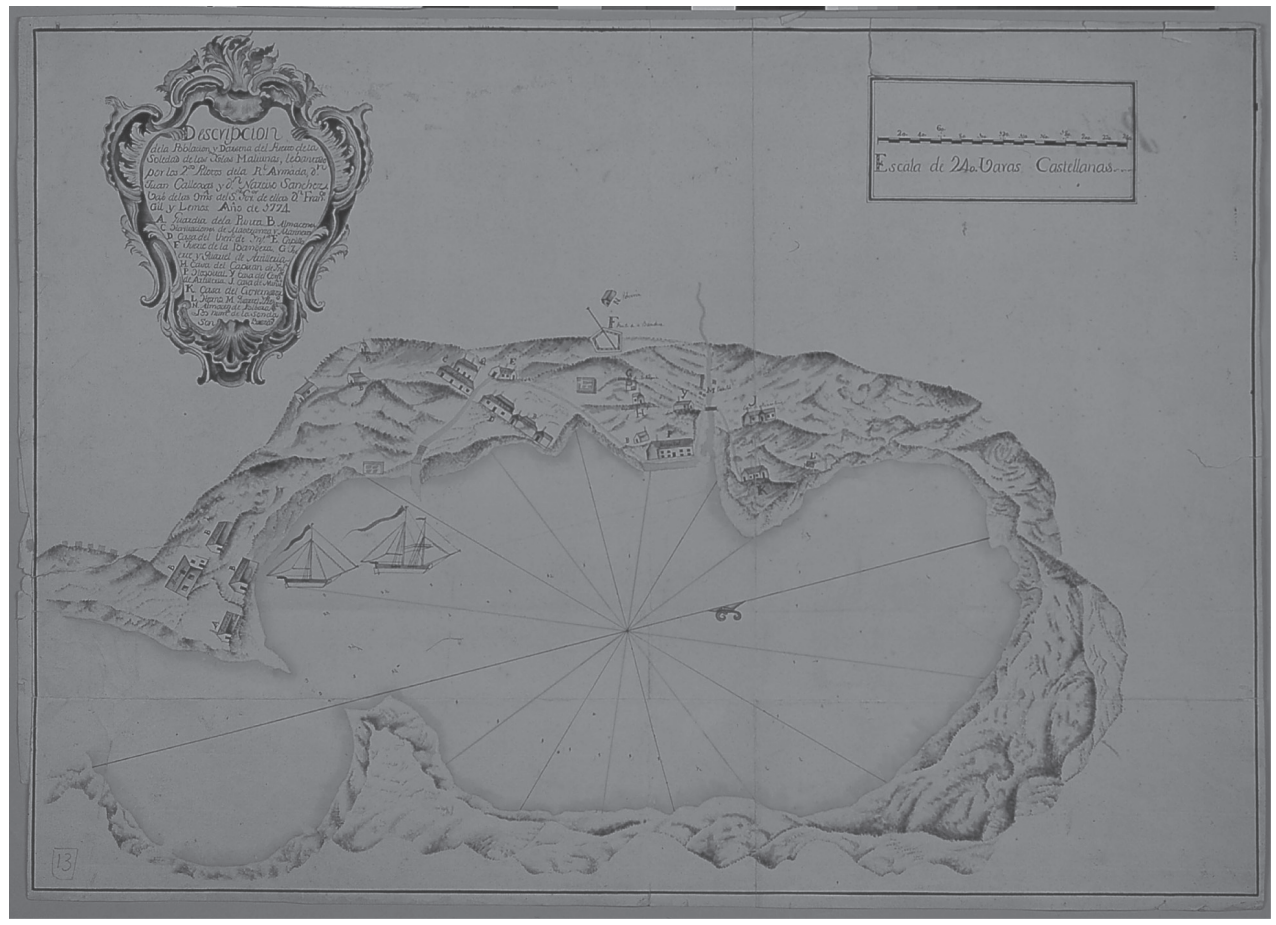

Figura 1. Plano de Puerto Soledad elaborado en 1774 por los pilotos de la Real Armada Juan Callejas y Narciso Sánchez por orden del gobernador, Francisco Gil y Lemos

Pese a su apreciación negativa sobre el estado de la colonia, tampoco parece que en los años siguientes se llevaran a cabo grandes reformas. Comparando el inventario elaborado por don Francisco en 1774 y el que elaboraría su sucesor en 1777, se aprecia que en los tres años que regiría los destinos de la colonia ésta no experimentaría modificaciones significativas, desapareciendo solamente tres edificaciones menores como resultado de la partida de algunos colonos y menguando la población de 115 a 84 habitantes ${ }^{46}$. Todo ello no deja de ser coherente con sus propuestas de reforma de la misma, tendentes a reducirla a su mínima expresión, si bien tampoco se puede descartar que la desazón omnipresente le afectara, al igual que a la mayoría de los hombres destinados en Puerto Soledad. Los archivos guardan silencio sobre esta cuestión, puesto que al igual que abundan las cartas quejosas de su antecesor Ruiz Puente, Gil y Lemos, si es que estaba desanimado o desesperado, prefirió no dejar rastro alguno de sus cuitas.

46 AGI, Buenos Aires, 553. Informe de Ramón de Carassa, 15 de febrero de 1777. 


\section{LA EVACUACIÓN DE PORT EGMONT POR LOS INGLESES}

La principal cuestión en estos momentos era la promesa británica de evacuar Port Egmont. A este fin Gil y Lemos organizó regularmente expediciones para observar los movimientos británicos. Éstas se llevaban a cabo con el máximo sigilo, como demuestran las siguientes instrucciones que entregó el gobernador al pilotín de la Real Armada, Simón Fernández Pellón:

«Procurando en esta operación ocultarse cuanto sea factible por las graves resultas que pueden seguirse, y de que será responsable [...] en los viajes de ida y vuelta no tirarán fusilazos que puedan incendiar los campos, y llamar la atención a los ingleses, ni dejarán vestigios por donde puedan éstos colegir que han sido observados [...] Si por un remoto accidente durante la campaña de tierra encontrare algunos individuos de la colonia inglesa, y le preguntaren a qué fin se dirige aquella expedición responderá que a buscar un soldado, y un indio desertores de esta colonia, cuyos vestigios se hallaron por tierra hasta aquel estrecho, como se persuade, informará la carta auxiliar mía para aquel gobernador, que les exhibirá, y dirá tiene orden para entregar en propia mano ${ }^{47}$.

Aunque la pequeña expedición liderada por Fernández Pellón sufrió la deserción de un artillero llamado Roque Sierra —que se pasaría a los ingleses-, al menos logró su objetivo de observar Port Egmont e incluso elaborar un plano del $\mathrm{mismo}^{48}$. Estas expediciones que, una vez cruzado el Estrecho de San Carlos, que separaba las dos islas principales del archipiélago, se realizaban campo a través para poder acercarse a la colonia británica sin ser detectados, presentaban la dificultad añadida de la topografía de la isla, con sus famosos «ríos de piedra» 49 , sus marismas y pantanos, además de que en invierno llegaban a hacerse «intransitables estos desiertos por la creciente de los muchos arroyos con las aguas, y nieves, y porque éstas aflojan, y falsean el terreno», según relataría Gil y Lemos ${ }^{50}$.

En mayo de 1775 volvía a informar al gobernador de Buenos Aires de que «en cumplimiento de la Real Orden de 9 de abril de 1774 dispuse [un] segundo reconocimiento del Puerto de Egmont, y habiéndolo ejecutado en 2 de marzo de este año por distinta, y más penosa vereda a fin de evitar algún encuentro con los ingleses; se observó, que éstos mantienen aquel establecimiento en los mismos términos que lo tenían cuando se hizo el primero; subsistiendo en él una fragata desarmada, como lo estaba entonces ${ }^{51}$. No sería hasta el 31 de enero de 1776

47 AGI, Buenos Aires, 553. Instrucción que debe observar el $2^{\circ}$ piloto de la Real Armada y capitán de este puerto don Simón Fernández Pellón en la expedición que va a ejecutar por tierra desde el Estrecho de San Carlos hasta el Puerto Egmont en la colonia inglesa. Francisco Gil y Lemos, Puerto de la Soledad, 5 de noviembre de 1774.

48 AGI, MP Buenos Aires, 103 bis.

49 MAESO BUENASMAÑANAS (Madrid, 2004): 60.

50 AGI, Buenos Aires, 553. Carta de Francisco Gil y Lemos a Julián de Arriaga, Puerto Soledad, 16 de diciembre de 1774 .

51 AGI, Buenos Aires, 55. Despacho n 455 de Juan José de Vértiz a Julián de Arriaga, Montevideo, 31 de julio de 1775. 
cuando Gil y Lemos pudiese informar que «no me persuado haya duda, según lo que se deduce, en que la nación británica despobló aquel establecimiento»52.

Mayúsculo debió ser el susto cuando, en febrero de 1776, el bergantín San Francisco de Paula, en visita rutinaria a Port Egmont para verificar la ausencia de ingleses, descubrió un buque, al parecer de esa nación, en la bahía:

«Reconoció estar anclado en el puerto inglés, otro bergantín sin insignia de su nación: esta novedad, y el régimen, que dedujo de las instrucciones, que yo le di, le hicieron frecuentar la vigía por espacio de cinco días seguidos, por si en ellos notaba movimiento que manifestase su designio, y sólo pudo persuadirse de ver dos lanchas que repetidamente iban, y venían de abordo, y la disposición del barco estar cargando efectos (que a ser así) no podían ser otros, que los que se hallaban allí como abandonados en la antecedente descubierta: vino a darme parte, y sin más dilación que la precisa para habilitarle de víveres, le he vuelto a enviar al pleno conocimiento, y decisión del asunto, y habiéndole visto esta segunda vez aún constante, se detuvo con el bergantín oculto, y diario cuidado de vigilarle, por espacio de siete días, al cabo de los cuales halló haberse hecho a la vela, bajo de cuya certeza pasó el citado Peña al puerto informándose por menor, como que estaba exhausto de pobladores ${ }^{53}$.

Aunque todo parecía indicar que los ingleses habían abandonado para siempre Port Egmont, las autoridades españolas seguían preocupadas por sus actividades en la zona, razón por la cual las islas no serían evacuadas por España hasta 1811, en plena Guerra de la Independencia ${ }^{54}$. Ya en 1776 el virrey del Perú había advertido sobre las actividades de unos barcos balleneros — procedentes al parecer de Boston-, que se suponía estaban faenando por aguas de las Malvinas $^{55}$. A medida que el siglo se acercaría a su fin la cuestión de los balleneros extranjeros en aguas del Atlántico sur y del Pacífico se tornaría cada vez más acuciante para las autoridades coloniales españolas, lo que también justificaría la continuada presencia en dichas islas. Por otro lado, y aunque nuestro embajador en Londres no les otorgase mayor credibilidad, Arriaga informaría a Gil y Lemos el 2 de abril de 1776 sobre los rumores que circulaban en los cenáculos londinenses sobre una posible expedición de más de veinte embarcaciones cuya salida se

52 AGI, Buenos Aires, 56. Carta de Francisco Gil y Lemos a Juan José de Vértiz, Puerto Soledad, 31 de enero de 1776. Los ingleses dejaron una inscripción grabada en plomo para que quedara constancia de que seguían reclamando la soberanía de las islas, con el siguiente texto: «Be it known to all Nations. That Falkland's Island with this Fort, the Storehouses, Wharfs, Harbours, Bays and Creeks thereonto belonging, are the sole Right and Property of his most Sacred Majesty George the third, King of Great Britain, France and Ireland, Defender of the Faith \& Witness whereof this plate is set up and his Britannic Majesty's Colours left flying as a mark of possession by S.W. Clayton Commanding Officer at Falkland's Island. A.D. 1774».

53 AGI, Buenos Aires, 56. Despacho n 522 de Juan José de Vértiz a Julián de Arriaga, Montevideo, 27 de julio de 1776, citando una carta de Gil y Lemos a Vértiz de 10 de mayo de 1776.

54 DESTEFANI, 1982, 59.

55 AGI, Buenos Aires, 56. Carta de Juan José de Vértiz a José de Gálvez, Montevideo, 8 de junio de 1776 . 
decía inminente en dirección a las islas Falkland ${ }^{56}$. Sin embargo, y pese a esos rumores, ese mismo año los ingleses, cada vez más enfangados en la rebelión de sus colonias norteamericanas, comunicaban oficialmente a España el abandono del establecimiento de Port Egmont ${ }^{57}$. Las Malvinas se habían convertido en un lujo que en aquellas circunstancias ya no se podían permitir.

\section{UN BUQUE PORTUGUÉS NAUFRAGA EN LAS MALVINAS}

La existencia en Puerto Soledad debió hacerse tediosa para Gil y Lemos, al igual que lo era para sus hombres. La vida en la isla era dura y monótona, con la instrucción diaria de las tropas, los servicios religiosos asegurados por sus dos capellanes y, como principales pasatiempos, las cartas y la caza ${ }^{58}$. El principal sostén de la disciplina en la colonia debía ser la ausencia de escapatoria posible para sus hombres, lo que no impidió, como hemos visto, deserciones y conatos de motines, barómetro de la desesperación reinante. No obstante, incluso en paraje tan dejado de la mano de Dios como ése, de vez en cuando se producían acontecimientos sorprendentes que rompían la insufrible monotonía. Uno de ésos, el más sonado de los años de Gil y Lemos en la isla, fue el naufragio de un buque luso en sus costas en diciembre de 1774. Los portugueses, al parecer integrantes del Regimiento Fijo de Pernambuco que habían naufragado camino de Río de Janeiro, se salvaron de una segura muerte en tan inhóspito lugar gracias a la guarnición de Puerto Soledad. Según informaba un capitán de dicho regimiento que encontraron los españoles deambulando por la isla:

"Que en una costa de esta isla dejaban abandonada la zumaca nombrada Carneyro en que milagrosamente, y sin saber a dónde, habían llegado, faltosos de víveres, y con noventa días de navegación: que lo seguían un teniente, un alférez, y cincuenta y seis hombres de tropa, y marinería: que en la playa quedaban imposibilitados un capitán y veintidós hombres; que otros dos se habían muerto en la mar; y que el resto a noventa y cuatro plazas en todos los consideraba perdidos, o muertos en estos campos por donde traían doce días de camino»59.

Los veintidós hombres que luego recogieron en la playa se encontraban «imposibilitados de moverse por la extrema necesidad, y algunas enfermedades que les causó la hierba, y carne de lobos marinos de que se mantenían». No es de extrañar que «no dudaron los perdidos entregarse totalmente a la tropa; antes bien apreciaron como humanidad el que los buscasen, y socorriesen». Al final se logró

56 AGI, Buenos Aires, 553. Carta del príncipe de Masserano al marqués de Grimaldi, Londres, 7 de marzo de 1776. Carta de Francisco Gil y Lemos a José de Gálvez, Malvinas, 31 de enero de 1777.

57 AGI, Buenos Aires, 553. Carta de Juan José de Vértiz a José de Gálvez, Buenos Aires, 7 de noviembre de 1776 .

58 DESTEFANI, 1982, 63.

59 AGI, Buenos Aires, 553. Informe de Francisco Gil y Lemos a Julián de Arriaga, Malvinas, 18 de enero de 1775 . 
salvar, gracias a las patrullas que mandó por toda la isla Gil y Lemos, un total de 98 portugueses, muchos de ellos en estado lamentable.

La llegada, repentina e inesperada, de un número tan elevado de náufragos indudablemente presentó un importante problema logístico para la pequeña colonia. También planteaba, al menos en un principio, ciertos interrogantes para la seguridad del establecimiento, ya que los ingleses aún seguían por esas fechas en Port Egmont y las relaciones con Portugal, su principal aliado en la zona, eran difíciles debido a las constantes incursiones lusas en territorio español. No en vano la famosa expedición de Pedro de Cevallos contra la Colonia de Sacramento, la más numerosa de nuestra historia colonial, se organizaría escasamente dos años más tarde ${ }^{60}$. Por ello, en un principio y según relata el propio don Francisco: «Dudoso si sería verdadera la relación de los portugueses, con reflexión al actual estado de su nación en estas Américas, o acaso cautelosa, y con determinación de algún asalto maquinado en el Puerto de Egmont, como más próximo a éste, hice municionar toda la tropa, y que saliese inmediatamente a buscarlos, dando orden al capitán don Pedro Amores que la comandaba para que apoderándose de ellos, y de las armas, y tomando las más oportunas precauciones, los trajese a mi disposición». Sin embargo el estado lamentable de la misma — «su vista el objeto más digno de compasión»- pronto desarmó sus temores, y «la misma noche alojé a los oficiales en tierra, y a la tropa, y marinera en dos zumacas por falta de cuarteles, y a uno y otros se les asiste en los mismos términos, que a la oficialidad y tropa de esta guarnición» 61 .

Gil y Lemos, quien informaba que «su existencia en esta colonia es perjudicial, tanto por no haber tropa que los custodie, cuanto por que los víveres son sólo correspondientes a la dotación de ella» ${ }^{62}$, trató a los pobres desgraciados con suma humanidad. Gracias a sus desvelos y a los de la guarnición española, el 10 de junio de 1775 llegaban los últimos portugueses sanos y salvos al Río de la Plata $^{63}$. De ahí, Vértiz, «atendiendo a la inalterable buena correspondencia que por nuestra parte se procura mantener con esta nación», los hizo «conducir a la Colonia del Sacramento " ${ }^{64}$. Gil y Lemos, en un gesto característico del probo funcionario que siempre fue, los había encaminado al continente acompañados de una «relación individual de todo el gasto que durante su permanencia en esta isla han causado a la Real Hacienda»65, para que desde Buenos Aires se procediera a reclamar a la Corona de Portugal su reintegro.

60 DESTEFANI, 1982, 18.

61 AGI, Buenos Aires, 553. Informe de Francisco Gil y Lemos a Julián de Arriaga, Malvinas, 18 de enero de 1775 .

62 lbíd.

63 AGI, Buenos Aires, 553. Carta de Juan José de Vértiz a Julián de Arriaga, Montevideo, 31 de julio de 1775

64 AGI, Buenos Aires, 553. Carta de Juan José de Vértiz a Julián de Arriaga, Montevideo, 14 de marzo de 1775.

65 AGI, Buenos Aires, 553. Informe de Juan de la Piedra, Puerto Soledad, 20 de abril de 1775. 


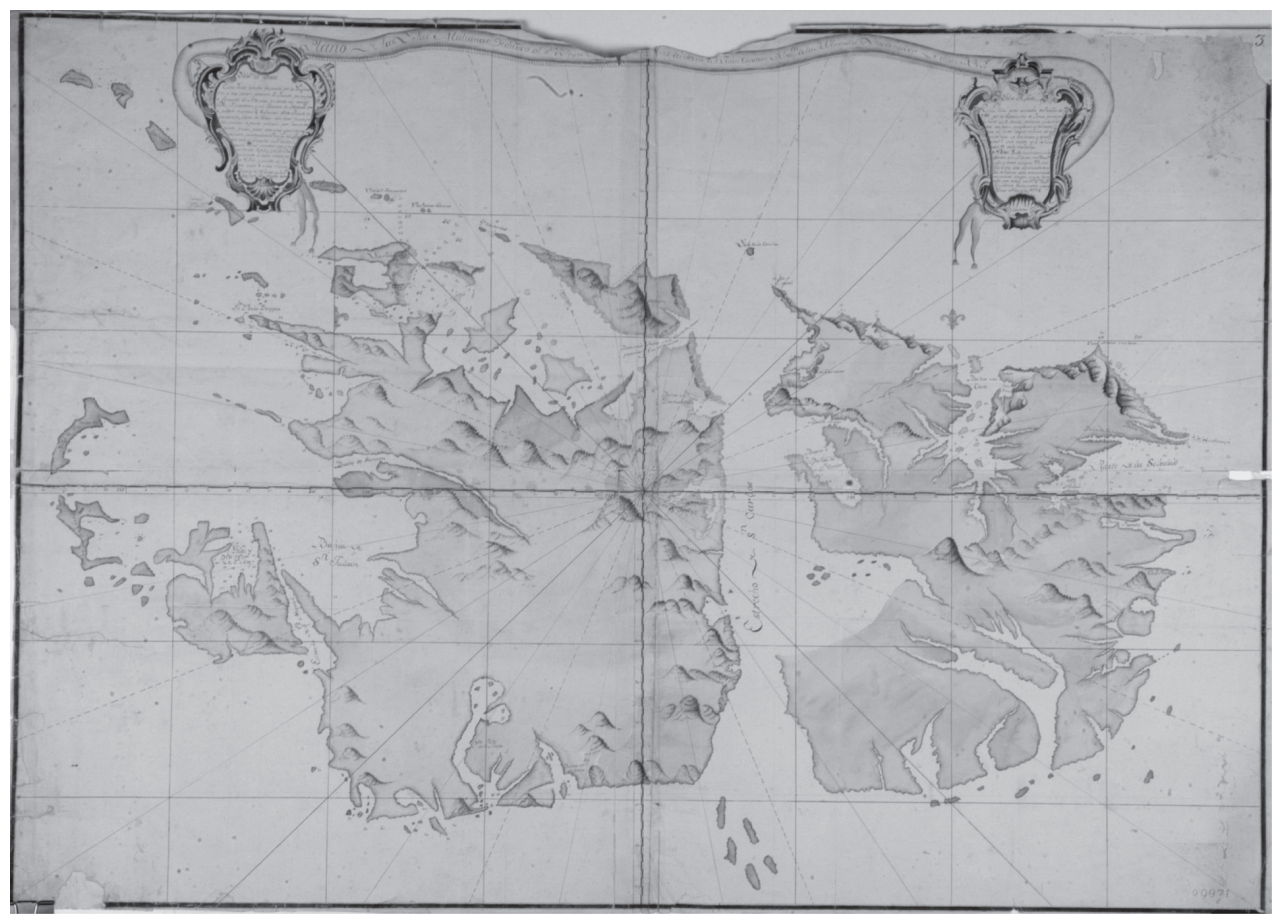

Figura 2. Plano de las Malvinas elaborado durante el mandato de Francisco Gil y Lemos ${ }^{66}$

\section{ALL'S WELL THAT END WELL}

«Certificamos que siendo llamados a consulta de la enfermedad que padece y ha padecido desde muchos años a esta parte el Sr. Gobernador de estas islas don Francisco Gil y Lemos a quien hemos curado en varias campañas que bajo sus órdenes hicimos así en Europa como en América hemos hallado que lejos de sujetarse a medicina dicha enfermedad va en aumento según lo testifican sus síntomas que son tanto más frecuentes e importunos cuanto más opuesto es a su temperamento el de este clima por los excesivos fríos y sequedad que se experimentan en él; por lo que conformes en un mismo dictamen somos de parecer que a no mudar de clima será cortísimo el número de días que sobreviva o se inhabilitará del todo para continuar el real servicio porque siendo la causa el afecto morboso que padece y ha padecido la suma rigidez de los sólidos natural en dicho enfermo nos asegura lo mismo que llevamos expuesto ${ }^{67}$.

Juan Real e Ignacio Dondeo, cirujanos.

66 AMN, 48-d-4.

67 AGI, Buenos Aires, 553. Informe médico de 10 de enero de 1776. MARTíN GARCÍA (Madrid, 1999): 437/438. Probablemente se tratara de la famosa «constipación de vientre», enfermedad que, según este autor «parecía ser bastante común entre los navegantes de la época y que no era otra cosa que un acusado estreñimiento». 
Tal vez fuera una mera coincidencia, pero la verdad es que sorprende que en el mismo correo en el que Gil y Lemos informaba de la evacuación de Port Egmont por los ingleses, elevara una instancia - acompañada del citado dictamen médico - solicitando su relevo en el mando. Es difícil saber hasta qué punto sus quejas obedecían a un mal objetivo, o al deseo subjetivo de no perpetuarse en un puesto que, a más de incómodo, acababa de perder gran parte de su interés estratégico. Lo que sí es indudable es que alegar enfermedades era un recurso bastante frecuente en la época, al que ya había recurrido en 1770 su antecesor, Ruiz Puente, si bien para su desgracia con escaso éxito ${ }^{68}$. Sea como fuere, el 10 de enero de 1776 don Juan Real, cirujano de la Real Armada destinado en la isla, y don Ignacio Dondeo, el cirujano de la urca Nuestra Señora de Regla, expedían el citado diagnóstico, recomendando su pronto regreso a España.

Parece que toda la familia se volcó en apoyo de su instancia. El 16 de julio de 1776 su hermano Benito escribía al nuevo ministro de Marina, Pedro González de Castejón, a quien, tras solicitar plazas de guardia marinas para dos de sus hijos, le añadía:

«No es éste solo el favor que pido a la generosidad de V.E. Mi hermano me escribe en este último correo de Buenos Aires, que de resulta de haber aguantado el invierno más riguroso que allí se acuerda (pues estuvieron ocho meses cubiertos de nieve) ha padecido tanto su salud, que se ve en la necesidad de representarlo, a fin de que se le saque de aquel destino, con permiso de venir a España, para recobrar la salud perdida, y seguir su carrera; como conozco su carácter me recelo mucho que su mal sea más de lo que me dice, cuando llegó a hacer representación ésta, vendría a la Secretaría de Indias, porque no podía tener noticia del empleo que V.E. tan justamente ocupa; el Sr. Gálvez no lo conoce, y por lo mismo mirará con indiferencia la expresada representación. Yo movido del amor que tengo a este único hermano me determino a escribir este correo a dicho Sr. Gálvez, pero no me adulo, que mi carta pueda producir el efecto deseado; tengo sí, una firme esperanza que V.E. querrá por su bondad dispensarle su protección, por cuyo medio logrará lo que desea» 69 .

A esta instancia se sumaría unos meses más tarde otra remitida por su anciana madre, pidiendo también «su relevo, con el objeto de restablecer su salud y lograr el fin de continuar sus servicios en la carrera que con tanto amor ha entablado, y espera finalizar ${ }^{70}$. Aunque años más tarde, siendo virrey del Perú, Gil y Lemos escribiría que «cuando promuevo a un empleado de uno a otro destino sin separarlo de su profesión, y ejercicio, e insisto en el cumplimiento es porque así me han tratado a mí mismo, y ése es todavía el trato que espero: es porque sobre esa única base se ha fundado, y apoyado el orden de subordinación que existe, es

68 AGI, Buenos Aires, 552. Memorial de Felipe Ruiz Puente, Malvinas, 3 de agosto de 1770.

69 AGS, Marina, legajo 91. Carta de Benito Gil y Lemos al marqués González de Castejón, Santiago de Compostela, 16 de julio de 1776.

70 AGI, Buenos Aires, 553. Carta de María Josefa de Lemos y Taboada al marqués González de Castejón, Santiago de Compostela, 26 de septiembre de 1776. 
porque si se consultaran las conveniencias, caprichos, e intereses particulares de los que están pagados para servir donde, como y cuando los necesiten, no hubiera obediencia, subordinación ni respeto » ${ }^{71}$, parece que en esta ocasión, al menos, se le trató con más benevolencia. El 9 de agosto de 1776 se cursaban instrucciones al gobernador de Buenos Aires concediendo licencia a Gil y Lemos para dirigirse a España ${ }^{72}$. A principios de febrero de 1777 , es de suponer que con gran alivio, entregaba el mando de las islas a don Ramón de Carassa y se restituía al Río de la Plata.

Su salida coincidía, además, con una reforma en profundidad del gobierno de las Malvinas. Siguiendo las recomendaciones que él mismo había planteado hacía tres años, se suprimía la figura de gobernador de las islas, responsabilidad que pasaría al capitán de la fragata destinada en Puerto Soledad, y se establecía el siguiente sistema de gobierno:

«Mediante haberse verificado ya por la Corte de Londres la evacuación del establecimiento, que hizo en la Gran Malvina, y ser constante, que la situación, y esterilidad de aquellas islas hace impracticable toda población, e imposibilita la subsistencia de otros individuos, que los que el rey mantenga a sus propias expensas, ha resuelto S.M. sobre el concepto de que deben continuar en todo tiempo dos fragatas destinadas al resguardo de este Río de la Plata, y a la conservación de Malvinas, se observe puntualmente la instrucción, que firmada de su mano acompaña V.S.I. adjunta, reducida a la continua existencia de una de ellas en aquella colonia con dos zumacas, o bergantines, que cuando se tenga por conveniente, y en las estaciones oportunas recorran con cautela y disimulo la costa y puertos para observar lo que pueda ocurrir de asegurarse de si efectivamente no vuelven los ingleses en lo sucesivo a su antiguo establecimiento ${ }^{73}$.

Abandonada la isla por los ingleses, establecido el gobierno de las islas de acuerdo con las nuevas pautas que él mismo había propuesto, su salida de las Malvinas fue, indudablemente, por la puerta grande.

El 17 de febrero de 1776, con 42 años de edad, había ascendido a capitán de navío ${ }^{74}$, si bien dicho ascenso formaba parte de una promoción general de la Armada, con motivo de una ampliación del escalafón llevada a cabo ese año y probablemente nada tuviera que ver con su labor en Malvinas ${ }^{75}$. Esta ampliación del

71 AGI, Lima, 705. Despacho n 141 de Francisco Gil y Lemos a don Diego Gardoqui, Lima, 23 de noviembre de 1793.

72 AGI, Buenos Aires, legajo 553. Borrador de carta del marqués González de Castejón a Juan José de Vértiz, San Ildefonso, 9 de agosto de 1776.

73 AGI, Buenos Aires, 554. Carta de Juan José de Vértiz a José de Gálvez, Buenos Aires, 7 de Noviembre de 1776. MAESO BUENASMAÑANAS (Madrid, 2004): 466 y 528. Según este autor, unos años más tarde se abandonarían por las mismas razones diversos establecimientos creados en la costa patagónica (Puerto Deseado, San Julián y San José), que llegaron a consumir el 25\% del presupuesto del virreinato de Buenos Aires.

74 ACT, Casa de Des, caja 5, legajo 1.

75 AGS, Marina, legajo 342. Promoción de 20 capitanes de fragata a capitanes de navío, y 5 a este grado: y de 50 tenientes de navío a capitanes de fragata, y 2 a esta graduación. 7 de febrero de 1776. 
número de oficiales de la Armada, muy ambiciosa al prever un incremento en 314 oficiales y jefes, tendría como corolario la creación ese mismo año de dos nuevas compañías de guardias marinas, en Cartagena y en El Ferrol, que se sumarían a la existente en Cádiz y que deberían surtir a la Real Armada de los jóvenes oficiales adicionales que requería este nuevo y ambicioso pie. Todo parece indicar que la recompensa por los años en las Malvinas fue su nombramiento, el 19 de noviembre de 1776, como capitán de la nueva compañía de El Ferrol ${ }^{76}$. Era éste un cargo codiciado, que gozaba de gran prestigio intelectual en el cuerpo y que debía atraer a un oficial científico como Gil y Lemos, émulo de Jorge Juan. Por añadidura, sabemos que Gil y Lemos no fue el candidato preferido ni de Andrés Reggio, director general de la Armada, ni de Francisco Xavier de Winthuysen, comandante de la compañía de Cádiz y que se convertía ahora en comandante del cuerpo en su conjunto ${ }^{77}$. Ello daría a entender que la decisión fue tomada al máximo nivel, por el nuevo ministro de Marina, el marqués González de Castejón, o incluso, aunque parece más improbable, por el mismísimo Carlos III. Resulta significativo que simultáneamente el mando de la compañía de Cartagena se concediera a José de Mazarredo, a quien muchos historiadores navales consideran el marino español más sobresaliente del siglo XVIII ${ }^{78}$.

Los duros años en Malvinas no habían pasado en vano y le debieron franquear ciertas puertas en Madrid, ya que años más tarde su sucesor en Puerto Soledad, Ramón de Carassa, escribiría a Carlos III recordándole que, «a los antecesores en dicho gobierno don Felipe Ruiz Puente, y don Francisco Gil, les fue de particular mérito el servicio hecho en las citadas Malvinas, y han sido recompensados con preferencia, así en la carrera de la Armada, como por otros medios con que se ha dignado atender la piedad de V.M ${ }^{79}$.

El nuevo reglamento de la Real Armada ampliaba el escalafón a 57 capitanes de navío, frente a los 38 existentes en ese momento. El número de capitanes de fragata debía pasar de 71 a 106, el de tenientes de navío de 151 a 194, el de tenientes de fragata de 91 a 188, el de alféreces de navío de 114 a 253 y el de alférez de fragata reducirse de 317 a 298. En total una ampliación del número de oficiales y jefes en 314 hombres.

76 AGM, legajo 2854, libro de 1776. ACT, Casa de Des, caja 5, legajo 1.

77 AGS, Marina, legajo 90. Andrés Reggio, el 18 de octubre de 1776, recomendaba para la Compañía de El Ferrol en primer lugar a Antonio Valdés, incluyendo asimismo en la terna, por orden de preferencia, a Atanasio Varanda y a Francisco Morales. Para Cartagena recomendaba a José de Mazarredo, seguido por Ignacio Mendizábal y, como tercero en la terna, a Francisco Gil. Por su lado, el 1 de octubre de 1776 Winthuysen recomendó a Alberto Olaondo para El Ferrol, seguido por Pedro de Cárdenas y con Mazarredo cerrando la terna. Para Cartagena proponía, por orden de preferencia, a Ignacio Duque de Estrada, a Juan Basurto y finalmente a Antonio Valdés, por esas fechas sólo capitán de fragata, aunque el cargo estaba reservado para un capitán de navío.

78 Archivo Condal de Motrico (ACM), Cosme de Churruca, folio 787. Carta de José de Echea a Francisco de Churruca, Cádiz, 20 de noviembre de 1776. Es significativo que por esas fechas ya se supiera en Cádiz del nombramiento de Mazarredo para la Compañía de Cádiz, pero no del de Gil y Lemos para El Ferrol, lo que parecería indicar que fue una decisión tomada en último momento.

79 AGI, Buenos Aires, 553. Súplica de Ramón de Carassa a S.M. de 10 de diciembre de 1785. Felipe Ruiz Puente sería ascendido a intendente del departamento marítimo de Cádiz a su vuelta de Malvinas. 


\section{BIBLIOGRAFÍA}

ANDÚJAR CASTILLO, Francisco, Los militares en la España del siglo XVIII. Un estudio social, Granada, Universidad de Granada, 1991.

BLANCO NÚÑEZ, José María, La Armada española en la segunda mitad del siglo XVIII, Madrid, IZAR Construcciones Navales, 2004.

BOURGOING, Jean-Francois, Tableau de l'Espagne moderne, vol. II, París, Chez Levrault frères, 1803.

CAPEL, Horacio "Geografía y cartografía», en Antonio Lafuente, José Luis Peset y Manuel A. Sellés (eds.), Carlos III y la ciencia de la llustración, Madrid, Alianza Editorial, 1988, 99/126.

CERVERA PERY, José, La Marina de la llustración, Madrid, Editorial San Martín, 1986.

DESTEFANI, Laurio, The Malvinas, The South Georgias and the South Sandwich Islands, the conflict with Britain, Buenos Aires, Edipress S.A., 1982.

FERRER DEL RIO, Antonio, Historia del reinado de Carlos III en España, vol. III, Madrid, Imprenta de los Señores Matute y Compañía, 1856.

GIL MUNILLA, Octavio, Malvinas, el conflicto anglo-español de 1770, Sevilla, CSIC, 1948.

JOHNSON, Samuel, Thoughts on the Late Transactions Respecting Falkland's Islands, Londres, T. Cadell, 1771.

LA PARRA LÓPEZ, Emilio, Manuel Godoy. La aventura del Poder, Barcelona, Tusquets, 2002.

MAESO BUENASMAÑANAS, Juan Alfonso, Expediciones Navales Españolas a la Patagonia Argentina Durante el Siglo XVIII, tesis doctoral, Departamento de Historia Moderna de la UNED (Madrid, 2004).

MARTÍN GARCÍA, Alfredo, «Entre el mar y la muerte. Procedencias, condiciones de vida y mortalidad de los navegantes en el Real Servicio (1776-1804)», Espacio, Tiempo y Forma, IV/12 (Madrid, 1999): 415-441.

MARTÍNEZ MONTERO, Homero, El apostadero de Montevideo 1776-1814, Madrid, CSIC, 1968.

PALACIO ATARD, Vicente, El Tercer Pacto de Familia, Madrid, CSIC, 1945.

RATTO, Héctor R., Actividades marítimas en la Patagonia durante los siglos XVII y XVIII, Buenos Aires, Ministerio de Marina, 1930.

URTASUN, Valentín, Historia diplomática de América. La emancipación de las Colonias británicas, Pamplona, Imprenta Higinio Coronas, 1920. 
